\title{
ATIVIDADE RESPIRATÓRIA EM MITOCÔNDRIAS ISOLADAS DA POLPA DO MAMÃO UENF/CALIMAN 01 E TAINUNG 01 NA CONSERVAÇÃO DO FRUTO EM PÓS-COLHEITA ${ }^{1}$
}

\author{
LÍGIA RENATA ALMEIDA DA SILVA², GLÁUCIA MICHELLE COSME SILVA, \\ WILLIAN BATISTA SILVA ${ }^{4}$, CLÁUDIO LUIS MELO DE SOUZA ${ }^{5}$, \\ JURANDI GONÇALVES DE OLIVEIRA ${ }^{5}$
}

RESUMO - Este trabalho teve como objetivo comparar a atividade respiratória em mitocôndrias isoladas e os atributos físicos e químicos da polpa de dois híbridos de mamão, UENF/Caliman01 (UC01) e Tainung01, durante o amadurecimento dos frutos. $\mathrm{O}$ amadurecimento dos frutos não mostrou diferenças significativas entre os genótipos na luminosidade (L), no croma (C) e no ângulo hue da casca. A perda de massa (PM) e as firmezas do fruto (FF) e do mesocarpo (FM) diferiram entre os genótipos, sendo que a FF e a FM diminuíram com o tempo após a colheita, ao contrário da PM, que aumentou no mesmo período. A atividade respiratória nas mitocôndrias isoladas mostrou diferenças entre os genótipos quanto à respiração total (RT), sendo maior e decrescente no Tainung01 e constante no UC01 durante o amadurecimento dos frutos. Durante esse período, verificou-se que a participação da via oxidase alternativa (AOX) foi crescente, contra uma participação decrescente da via citocromo oxidase (COX) em ambos os híbridos, indicando um crescente desacoplamento das mitocôndrias, o que pode estar associado às rápidas transformações bioquímicas que acarretam a senescência do órgão. A partir desses resultados, sugere-se investigar materiais genéticos com menor atividade AOX, ou formas de minimizar a atividade respiratória nos frutos em pós-colheita. A AOX apresentou alta correlação positiva com a PM e negativa com a FF e a FM. O inverso foi observado para COX. A RT apresentou correlação positiva apenas com a FM. As correlações apontam a viabilidade de estimar a atividade respiratória por meio de análises mais simples, como a PM, a FF e a FM, facilitando a pesquisa na área.

Termo de indexação: amadurecimento, Carica papaya L., citocromo c oxidase, oxidase alternativa, respiração.

\section{RESPIRATORY ACTIVITY IN ISOLATED MITOCHONDRIA FROM THE PULP OF UENF/CALIMAN01 AND TAINUNG01 PAPAYA IN POSTHARVEST FRUIT CONSERVATION}

\begin{abstract}
This study had the object of comparing the respiratory activity in isolated mitochondria and the physical and chemical attributes of the pulp of two papaya hybrids, UENF/Caliman01 and Tainung01, during fruit ripening. The fruit ripening did not show significant differences between the genotypes with regard to lightness (L), chroma (C), and hue angle of the skin. The loss of mass (LM) and the firmness of fruit $(\mathrm{FF})$ and mesocarp (FM) differed between the genotypes, with FF and FM decreasing with time after harvest, while LM rose over the same period. The respiratory activity in the isolated mitochondria revealed differences between the genotypes with respect to total respiration (TR), being higher and with negative time-correlation function in Tainung01 and constant in UC01 during fruit ripening. During this period the participation of alternative oxidase (AOX) pathway was crescent, against the decreasing participation of cytochrome $\mathrm{c}$ oxidase (COX) pathway in both hybrids was verified, indicating an increasing uncoupling of the mitochondria, which may be associated with the rapid biochemical transformations that cause the senescence of the organ. From these results, investigating genetic materials with lower AOX activity or ways of minimizing the respiratory activity in postharvest fruit is suggested. The AOX presented the high positive correlation with LM and negative with FF and FM while the inverse was observed for COX. The TR presented positive correlation only with the FM. The correlations indicated the viability of estimated respiratory activity through simpler analyses such as LM, FF, and FM, thus facilitating studies in the area. Index terms: Ripening, Carica papaya L., cytochrome c oxidase, alternative oxidase, respiration.
\end{abstract}

\footnotetext{
(Trabalho 079-14). Recebido em: 28-02-2014. Aceito para publicação em: 10-11-2014.

${ }^{2}$ Mestranda em Genética e Melhoramento de Plantas - UENF/ Campos dos Goytacazes-RJ. E-mail: ligiarenata@agronoma.eng.br

${ }^{3}$ Doutoranda em Produção Vegetal pela - UENF / Campos dos Goytacazes-RJ. E-mail: glauciamichelle2006@yahoo.com.br;

${ }^{4}$ Mestrando em Produção Vegetal - UENF/ Campos dos Goytacazes-RJ. E-mail: williambatistadasilva@gmail.com;

${ }^{5}$ Professor na Universidade Estadual do Norte Fluminense Darcy Ribeiro - UENF/ Campos dos Goytacazes-RJ. E-mail: jugo@uenf.br; claudio.melo@ig.com.br
} 


\section{INTRODUÇÃO}

O mamão é caracterizado como um fruto climatérico por apresentar aumento na respiração, na fase de amadurecimento, o que contribui com a qualidade e a vida pós-colheita do fruto. Vários estudos têm sido realizados para ampliar o conhecimento dos processos bioquímicos envolvidos no desenvolvimento de frutos, com o objetivo de elucidar fatores passíveis de manipulação, controle ou interferência e possibilitar modificações que permitam estender a vida útil destes frutos (AZEVEDO et al., 2008).

O aumento na respiração dos frutos climatéricos está associado às mudanças no sistema de dissipação de energia nas mitocôndrias, levando à ativação de rotas mitocondriais alternativas, que aumentam a produção de calor em detrimento da fosforilação oxidativa. Há dois sistemas dissipadores de energia conhecidos em mitocôndrias vegetais, a via operada pela oxidase alternativa e a proteína desacopladora (UcP) (BORECKY;VERCESI, 2005). Já foram verificadas rotas mitocondriais alternativas, operadas por estes dois sistemas dissipadores de energia, durante o desenvolvimento de frutos de manga (CONSIDINE et al., 2001), maçã (DUQUE; ARRABAÇA, 1999), tomate (ALMEIDA et al., 2002) e tubérculos de batata (PINHEIRO et al., 2004).

A operação de sistemas dissipadores de energia tem a função de equilibrar a capacidade de geração de compostos necessários às diversas rotas de biossíntese na fosforilação oxidativa mitocôndrial. A respiração, além de gerar energia na forma de ATP, para a atividade celular, fornece também moléculas orgânicas fundamentais para várias rotas metabólicas que utilizam moléculas intermediárias da via respiratória para formar iniciadores, substratos e moduladores do metabolismo celular, fundamentais para o desenvolvimento vegetal (NUNES-NESI et al., 2010). No caso dos frutos, o desenvolvimento passa, impreterivelmente, pela fase do amadurecimento e encerra-se com a senescência desse órgão (SOUZA et al., 2014).

O mamão Tainung01, do grupo Formosa, é o principal híbrido explorado comercialmente no Brasil, totalizando $40 \%$ da área plantada no Estado do Espírito Santo (FERREIRA et al., 2011). O UC01, também conhecido por "Calimosa", foi o primeiro híbrido nacional lançado no mercado brasileiro, resultado do cruzamento entre genitores dos grupos Solo e Formosa. O mesmo apresenta, entre outras qualidades, alta produtividade e frutos com excelente qualidade de mesa, porém com vida útil mais curta que o Tainung01. Apesar das diferenças no aspecto de qualidade de polpa e vida útil, esses dois híbridos assemelham-se muito quanto à taxa respiratória e de produção de etileno avaliados durante o amadurecimento em frutos intactos (SOUZA et al., 2014).

O presente trabalho tem como objetivo avaliar a influência da atividade respiratória em mitocôndrias, isoladas da polpa do fruto, na conservação pós-colheita dos mamões UC01 e Tainung01.

\section{MATERIAL E MÉTODOS}

O experimento foi conduzido na Unidade de Bioquímica e Fisiologia Pós-Colheita (LMGV/ CCTA) da Universidade Estadual do Norte Fluminense Darcy Ribeiro (UENF), em Campos dos Goytacazes-RJ.

O material vegetal foi constituído dos híbridos de mamão Tainung01 e UC01, procedentes do cultivo comercial da empresa Caliman Agrícola $\mathrm{S} / \mathrm{A}$, na cidade de Linhares $\left(19^{\circ} 15^{\prime} \mathrm{S} ; 39^{\circ} 51^{\prime} 70^{\prime \prime} \mathrm{W}\right)$, Espírito Santo. Os frutos foram colhidos no estádio 0 de maturação (fruto maduro fisiologicamente com casca $100 \%$ verde) e, posteriormente, transportados para o laboratório, em caixas padronizadas, a uma temperatura de $15^{\circ} \mathrm{C}$, por cerca de $6 \mathrm{~h}$. Na chegada ao laboratório, os frutos foram sanitizados e armazenados em condições controladas de temperatura $\left(25 \pm 1^{\circ} \mathrm{C}\right)$ e umidade relativa $(85 \pm 5 \%)$.

As medições da coloração da casca foram realizadas, utilizando-se de um colorímetro portátil (Chroma Meter, modelo CR-300, Minolta). Foram realizadas três leituras em pontos equidistantes, na região equatorial do fruto, utilizando-se do valor médio para os seguintes atributos de cor, segundo as coordenadas CIELab: luminosidade, parâmetro $\mathrm{L}$; croma, $\mathrm{C}=\left[(\mathrm{a})^{2}+(\mathrm{b})^{2}\right]^{1 / 2}$, e ângulo hue, segundo descrição de McGuire (1992). Foram realizadas três repetições, sendo cada repetição um fruto.

As medidas da firmeza do fruto (FF) e do mesocarpo (FM) foram obtidas como a força máxima de penetração para a ruptura do tecido e determinadas, usando-se uma ponta de prova de 8 $\mathrm{mm}$ x $8 \mathrm{~mm}$. Com o auxílio de um penetrômetro digital de bancada, Fruit Pressure Tester (TR TURONI, modelo 53205, Italy), foram tomadas quatro medições em pontos equidistantes, na região equatorial do fruto, salientando que a medida da FF foi realizada diretamente sobre o fruto, sem a retirada da casca, e para a FM foi feito um corte transversal na região equatorial a fim de se tomar medidas sobre o mesocarpo. Os resultados foram expressos em 
Newton $(\mathrm{N})$.

O teor de sólidos solúveis (SS) da polpa foi obtido usando-se gotas, extraídas com prensa de mão, de uma amostra retirada da região mediana do mesocarpo do fruto e aferida com refratômetro digital (ATAGO, PR201, France), sendo os resultados expressos em ${ }^{\circ}$ Brix. A acidez titulável (AT) foi determinada por titulometria com $\mathrm{NaOH}$ a $0,1 \mathrm{~N}$, utilizando o método do Instituto Adolfo Lutz (1985), e os resultados, expressos em \% de ácido cítrico. O "ratio" foi calculado usando-se a razão entre os teores de SS e AT (SS/AT), e usado como indicador amplo de qualidade. A quantificação do teor de ácido ascórbico (AA) foi realizada em amostras da polpa do mamão através de titulometria, de acordo com o método descrito pela AOAC (2002), com os resultados expressos em mg AA.(100 MF) $)^{-1}$.

As mitocôndrias foram isoladas a $4^{\circ} \mathrm{C}$, utilizando-se de cerca de $600 \mathrm{~g}$ da polpa dos mesmos frutos utilizados para as análises físico-químicas. O tecido foi homogeneizado em centrífuga (Juicer, modelo R16720, Walita, Brasil) com tampão (pH $7,4)$ para isolamento, constituído por $600 \mathrm{mM}$ de sacarose para o Tainung01 e $700 \mathrm{mM}$ para o UC01, acrescido de MOPS (50 mM), EDTA (3 mM), Cys (8 mM), BSA $(0,1 \% \mathrm{p} / \mathrm{v})$ e PVP-25 (0,4\% p/v). O material homogeneizado foi centrifugado a $1.500 \mathrm{~g}$ por $15 \mathrm{~min}$. A seguir, removeu-se o sobrenadante, que foi novamente centrifugado a $15.000 \mathrm{~g}$ por 15 minutos, sendo o precipitado ressuspendido em tampão (pH 7,2) de lavagem, contendo $600 \mathrm{mM}$ de sacarose para Tainung01 e $700 \mathrm{mM}$ para UC01, além de MOPS (10 mM), EDTA (0,5 mM), BSA (0,1\% $\mathrm{p} / \mathrm{v}$ ), e centrifugado a $1.000 \mathrm{~g}$ por $8 \mathrm{~min}$. Removeu-se o sobrenadante que foi, novamente, centrifugado a $9.000 \mathrm{~g}$ por $15 \mathrm{~min}$, para a obtenção das mitocôndrias no precipitado.

Na purificação das mitocôndrias, foi utilizado um gradiente em percoll de $\mathrm{pH}$ 7,2 contendo percoll $(22,5 \% \mathrm{v} / \mathrm{v})$, manitol (0,6 M), MOPS (10 mM) e BSA $(0,5 \% \mathrm{p} / \mathrm{v})$, que foi centrifugado a $12.000 \mathrm{~g}$ por 45 min. O procedimento seguiu o protocolo proposto por Duque e Arrabaça (1999), com modificações de Oliveira (2012).

A concentração de proteínas foi determinada espectrofotometricamente, a $480 \mathrm{~nm}$, utilizando o Kit 2-D quant (GE, USA - Bio-Sciences Corp) e BSA como proteína-padrão.

Foram utilizados $25 \mu \mathrm{g}$ e $50 \mu \mathrm{g}$ de proteína para a determinação da atividade respiratória das mitocôndrias isoladas da polpa do mamão Tainung01 e UC01, respectivamente. Foi utilizado o método polarográfico, usando um eletrodo de $\mathrm{O}_{2}$ tipo Clark (Hansatech, Respire 1, UK), em 0,6 mL de meio de reação [manitol $(0,35 \mathrm{M})$, tampão fosfato $(10 \mathrm{mM})$, $\mathrm{KCl}(10 \mathrm{mM}), \mathrm{MgCl}_{2}(5 \mathrm{mM}), \operatorname{BSA}(0,5 \% \mathrm{p} / \mathrm{v}), \mathrm{pH}$ $7,2]$, a $25^{\circ} \mathrm{C}$. Após a adição de 100 nmoles de ADP ao meio de reação, foram registrados os estados 3 e 4 da respiração, evidenciando a capacidade fosforilativa das mitocôndrias. O extrato de mitocôndrias purificadas foi testado quanto ao nível de integridade das membranas, segundo Sweetlove et al. (2007). Em todas as avaliações, o nível de integridade das mitocôndrias utilizadas foi superior a $80 \%$.

Foram utilizados malato $(10 \mathrm{mM})$ e glutamato (20 mM) como substratos respiratórios, e o meio de reação foi suplementado com $2,5 \mu \mathrm{g}$ de oligomicina e $300 \mu \mathrm{M}$ de propranolol para a inibição da ATPsintase e do canal aniônico, respectivamente, além de $1 \mathrm{mM}$ de ditiotreitol (DTT) e $0,15 \mathrm{mM}$ de piruvato para estimular a atividade AOX e BSA $(0,5 \%)$ para inibir a atividade UcP (CALEGARIO et al., 2003). Foi considerada como respiração total (RT) a taxa respiratória registrada em mitocôndrias no estado 4 (DUQUE; ARRABAÇA, 1999). A inibição da citocromo c oxidase foi realizada a partir da adição de $3 \mathrm{mM}$ de $\mathrm{KCN}$ ao meio de reação, enquanto a inibição da oxidase alternativa se deu pela a adição de $20 \mu \mathrm{M}$ de $n$-propil galato (PG). A respiração na presença apenas de $\mathrm{KCN}$ foi considerada a atividade respiratória da via oxidase alternativa (RAOX), sendo determinado o percentual de participação dessa via $(\mathrm{AOX})$ em relação à $\mathrm{RT}$,conforme expressão: $[\mathrm{AOX}=(\mathrm{RAOX} / \mathrm{RT}) \times 100]$. Após a adição de PG, toda a respiração paralisou, não sendo detectada respiração residual. A participação da via citocromo oxidase (COX) foi obtida pela diferença entre a RT e a AOX, considerando a RT como referência, igual a $100 \%$.

Utilizou-se do delineamento em bloco casualizado (DBC), em esquema fatorial $2 \times 5$ (2 genótipos e 5 tempos de amadurecimento, com intervalo de 1 dia, totalizando 9 dias) com 3 repetições. Para a análise dos parâmetros em função do tempo de amadurecimento, os dados foram submetidos à análise de variância para regressão, por meio do teste $\mathrm{F}(p \leq 0,05)$, e comparação de médias pelo intevalo de confiança $(p \leq 0,05)$. Foram submetidas à correlação de Pearson as variáveis relacionadas à atividade respiratória em mitocôndrias isoladas e os demais atributos físicos e químicos associados à qualidade dos mamões.

\section{RESULTADOS E DISCUSSÃO}

A PM dos mamões UC01 e Tainung01 diferiu $(p \leq 0,05)$ entre os genótipos, além de ter sido influenciada $(p \leq 0,01)$ pelo tempo após a colheita 
dos frutos, seguindo uma tendência linear $(p \leq 0,01)$ crescente, em ambos os híbridos (Figura 1). A PM dos híbridos foi de pouco mais de 1,0\% durante os nove dias de avaliação, o que não representa uma perda na qualidade dos frutos, segundo preconizam Chitarra e Chitarra (2005), que admitem até 10\% de PM fresca como fator limitante da qualidade de frutos. Santos et al. (2008) verificaram que, no mamão Tainung01 acondicionado em diferentes embalagens para o transporte, a PM fresca dos frutos foi crescente à medida que os frutos foram amadurecendo, independentemente das formas de embalagens. Resultados semelhantes foram encontrados por Pimentel et al. (2011) que, avaliando a conservação do mamão Havaí, utilizando películas comestíveis a diferentes temperaturas, verificaram a mesma tendência nos frutos que não receberam revestimento.

A coloração da casca dos frutos variou pouco entre os híbridos, com exceção para a L que foi menor no UC01 $(37,42)$, no primeiro dia de avaliação, em comparação ao Tainung01 (43,52) (Figura 2A). Durante o amadurecimento, verifica-se um aumento no brilho da casca, indicado pelo parâmetro $\mathrm{L}$, que em ambos os genótipos atingiu valores de aproximadamente 61 , aos nove dias, uma tendência já observada nesses mesmos híbridos (SOUZA et al., 2014) como em outros genótipos de mamão (PEREIRA et al., 2009; BASULTO et al., 2009). Isso indica que UC01 apresenta menor luminosidade que Tainung01 no início da pós-colheita, porém ambos atingem a mesma luminosidade após sete dias de armazenamento. Os resultados mostram que, com o tempo, após a colheita, o índice croma aumentou linearmente de modo significativo $(p \leq 0,05)$ entre o $1^{\circ}$ e o $9^{\circ}$ dia, com uma inversão nos valores, entre os genótipos, após o quinto dia de pós-colheita. Os valores observados para UC01 variaram de 22,3 a 53,7 durante o período de análise do amadurecimento do fruto, enquanto esses valores variaram de 27,3 a 49,6 no Tainung01 (Figura 2B). O ângulo de cor hue seguiu tendência semelhante em ambos os genótipos, mostrando declínio durante o amadurecimento, não sendo possível identificar diferenças entre os genótipos, inclusive no $9^{\circ}$ dia de armazenamento (Figura 1C). Os valores obtidos para UC01 variaram de 122,0 a $97,6^{\circ} \mathrm{h}$ do primeiro para o nono dia de póscolheita e entre 122,5 a $91,2^{\circ} \mathrm{h}$ para o Tainung 01 . O amadurecimento do mamão é marcado pelo aumento no brilho e mudança na cor da casca do verde para o amarelo, como indicado pelos parâmetros L, croma e ângulo hue. Tais mudanças resultam da degradação das clorofilas, bem como da síntese dos carotenoides, que acontecem com o amadurecimento do fruto.
Finalmente, cabe registrar que Souza et al. (2014) encontraram valores de hue variando de 90 a 120 ${ }^{\circ} \mathrm{h}$ em um período de sete dias de amadurecimento dos frutos de UC01 e Tainung01 em condições semelhantes às deste trabalho.

A FF e a FM diferiram $(p \leq 0,05)$ entre os genótipos, mostrando redução com o amadurecimento dos frutos (Figuras 3A e 3B). A FF variou entre 109,2 e 6,6 N no mamão UC01 e 122,3 e $10,9 \mathrm{~N}$ no Tainung01 (Figura 3A), enquanto a FM oscilou entre 85,6 e 2,5 N para o UC01 e 90,1 e 5,0 N para o Tainung01 (Figura 3B). Em ambos os híbridos, a perda na FF e na FM foi mais intensa até o quinto dia após a colheita. Entretanto, observa-se perda de FM um pouco mais acentuada no UC01, nos três primeiros dias, comparativamente ao Tainung01, o que pode significar maior amaciamento da polpa e menor resistência daquele híbrido ao manejo após a colheita. Fontes et al. (2008) observaram que 'Sunrise Solo' apresentou redução da firmeza mais acentuada que o 'Tainung01'. Esse decréscimo na firmeza dos frutos é indesejável para a comercialização por acarretar perdas consideráveis na fase de póscolheita.

A perda tanto na FF quanto na FM é decorrência de transformações bioquímicas durante o amadurecimento do fruto, principalmente o afrouxamento das microfibrilas de celulose e a decomposição da pectina que compõem a parede celular, por ação de enzimas pecto-hidrolíticas ativadas durante o amadurecimento dos frutos por ação do etileno (INIESTRA-GONZÁLEZ et al., 2013). A perda de firmeza pelos frutos é um fator limitante para o manejo dos frutos e para a aceitação pelos consumidores (CUQUEL et al., 2012).

Os resultados mostram diferença entre os genótipos na respiração total (RT) das mitocôndrias isoladas da polpa dos mamões (Figura 4). O híbrido Tainung01 apresentou uma RT decrescente ao longo do amadurecimento do fruto, passando de 340,8 para $170,5 \mathrm{nmol} \mathrm{O} \cdot \mathrm{mg}^{-1} \cdot \mathrm{min}^{-1}$, o que representa a redução de cerca de $50 \%$ na RT desse híbrido entre o início e o nono dia de armazenamento. Diferentemente, a RT nas mitocôndrias isoladas da polpa do híbrido UC01 não variou em função do tempo de armazenamento, porém foi menor $(p \leq 0,05)$ do que em Tainung01, registrando valor médio de $104,9 \mathrm{nmol} \mathrm{O}_{2} \cdot \mathrm{mg}^{-1}$. $\min ^{-1}$ desde o início até o nono dia após a colheita dos frutos (Figura 4).

Não foi possível observar a ocorrência de um pico na respiração total, a partir dos modelos de regressão utilizados, como seria esperado para o mamão (FONSECA et al., 2006; SOUZA et al., 2009; CORRÊA et al., 2011) por se tratar de um 
fruto climatérico. Todavia, registrou-se a maior taxa de RT no terceiro dia de armazenamento, apesar de não significativa, sugerindo que a avaliação se deu próxima ao pico climatérico ou que o pico climatérico é atípico ou pouco intenso. A não observância de um pico climatérico típico também foi constatada por Souza et al. (2014) para esses dois híbridos, porém usando métodos diferentes para quantificar a atividade respiratória. Enquanto Souza et al. (2014) usaram frutos intactos e quantificaram a produção de $\mathrm{CO}_{2}$ a partir de um analisador de gás no infravermelho, aqui foram utilizadas mitocôndrias isoladas, e a respiração, medida a partir do consumo de $\mathrm{O}_{2}$ usando um eletrodo de $\mathrm{O}_{2}$, tipo Clark. A variabilidade genotípica do mamão híbrido, devido ao seu alto grau de heterozigose, pode ser um dos fatores que influenciam na imprecisão da identificação do pico climatérico nesses frutos. Nesse caso, cada fruto híbrido, com sua carga genética única, apresenta uma taxa respiratória máxima em tempos distintos, não sendo possível a identificação de um pico climatérico na reunião desses dados para a obtenção de valores médios.

O registro da ocorrência do pico respiratório durante o amadurecimento dos frutos climatéricos pode variar, dependendo da técnica utilizada para a análise das trocas gasosas e do intervalo entre a tomada de dados. Corrêa et al. (2011) observaram um pico climatérico durante o amadurecimento do mamão 'Golden', empregando um analisador de gás no infravermelho para quantificar a produção de $\mathrm{CO}_{2}$. Porém, Souza et al. (2009), usando essa mesma técnica, não verificaram a ocorrência de qualquer pico respiratório durante o amadurecimento da mesma variedade de mamão, talvez devido à ocorrência desse pico entre as amostragens dos frutos. Por outro lado, Fonseca et al. (2006) e Resende et al. (2012) registraram dois picos climatéricos durante o amadurecimento do mamão 'Golden' usando a cromatografia gasosa para analisar a emissão de $\mathrm{CO}_{2}$, sendo o segundo pico considerado por Fonseca et al. (2006) o início da fase de sobreamadurecimento do fruto.

A participação da $\mathrm{AOX}$ e da $\operatorname{COX}$ na respiração dos frutos não diferiu $(p \leq 0,05) \mathrm{em}$ função do genótipo analisado (Figuras 5A e 5B). Os resultados mostram que a participação da $\mathrm{AOX}$ é crescente, enquanto a da COX é decrescente durante o amadurecimento de ambos os genótipos. No início do amadurecimento, a participação da AOX representava em torno de $35 \%$ da RT, chegando próximo de $84 \%$ ao final do amadurecimento (Figura 5A), enquanto a participação da COX seguiu tendência contrária, decrescendo aproximadamente de $65 \%$ para $16 \%$ no mesmo período (Figura $5 \mathrm{~B}$ ).

A expressiva participação da AOX na respiração do mamão, nos dois genótipos, pode ter causado um desacoplamento mitocondrial fisiológico, verificado a partir dos baixos valores $(1,2$ a 1,8$)$ do controle respiratório registrado (dados não apresentados) nas medidas da respiração em mitocôndrias isoladas. O desacoplamento das mitocôndrias resulta em menor resistência ao fluxo de elétrons na cadeia transportadora de elétron mitocondrial (CTEm), devido à redução no potencial de membrana (KADENBACH et al., 2010), tendo como consequência o aumento na taxa respiratória (MCDONALD, 2008). À atividade AOX, atribui-se principalmente a participação no controle do balanço entre a oxidação do substrato respiratório e o transporte de elétrons na CTEm, e no controle da geração de espécies reativas de oxigênio, além de sua participação na termogênese em algumas plantas, na resistência a estresses e certas patogenicidades e participação na reprogramação celular (ARNHOLDT-SCHMITT et al., 2006; MCDONALD, 2008; LI-JUN et al., 2010; XU et al., 2012; VANLERBERGHE, 2013). No amadurecimento de frutos, a AOX está associada ao aumento na respiração dos frutos climatéricos, juntamente com a proteína desacopladora (DUQUE; ARRABAÇA, 1999; VERCESI et al., 2006). Dessa forma, a possibilidade de minimizar a atividade da AOX pode ser uma maneira de influenciar no controle das transformações bioquímicas relacionadas ao amadurecimento, possivelmente prolongando a vida útil do fruto de mamão.

A Tabela 1 apresenta os dados da análise de correlação de Pearson $(p \leq 0,05)$ cujo objetivo foi estabelecer relações entre variáveis que normalmente são estudadas de modo segregado, mas que podem apresentar forte relação de causa e efeito, como no caso dos parâmetros físicos e químicos dos frutos e a atividade respiratória mitocondrial. Nota-se que a AOX apresentou alta correlação positiva com PM $(R=0,91)$ e negativa com a FF $(R=-0,72)$ e FM $(\mathrm{R}=-0,75)$. A COX apresentou tendências contrárias, ou seja, correlação negativa com a PM $(\mathrm{R}=-0,87)$ e positivas com FF $(R=0,60)$ e $F M(R=0,67)$. A $R T$ só apresentou baixa correlação com $\mathrm{FM}(\mathrm{R}=0,56)$.

Da literatura, sabe-se que, dentre as causas principais da perda da firmeza da polpa do mamão, está a degradação de protopectina da lamela média e da parede celular primária, o aumento da pectina solúvel e a perda de açúcares neutros não celulósicos (JACOMINO et al., 2002; THUMDEE et al., 2010). Esse fenômeno é modulado pela ação de hidrólise acontecendo paralelamente ao 
aumento da respiração e da emissão de etileno no mamão (SOUZA et al., 2009; THUMDEE et al., 2010). Sendo o etileno o hormônio diretamente envolvido com o amadurecimento, ele atua também regulando a capacidade da AOX (MAZORRA et al., 2013), o que justifica a alta correlação (superior a $70 \%$ ) verificada entre as firmezas do fruto e do mesocarpo, e a participação da AOX. Apesar de os dados aqui mostrarem uma correlação significativa entre a PM e a participação das vias AOX e COX, não foi encontrada correlação entre a PM e a RT, como sugerido por Santos et al. (2008) na avaliação do mamão Tainung01 transportado a granel e acondicionado em diferentes embalagens. Vale destacar, nesse caso, que Santos et al. (2008) não avaliaram a respiração em mitocôndrias isoladas, mas, sim, no fruto intacto, utilizando o princípio da cromatografia gasosa.

Com relação aos demais parâmetros físicos e químicos, a maioria não mostrou correlação significativa com os parâmetros relacionados com a atividade respiratória, exceto a AT, que apresentou baixa correlação significativa com a $\operatorname{COX}(\mathrm{R}=0,46)$.

Simplificando as observações, podemos dizer que a participação da AOX aumenta no processo de amadurecimento dos frutos, e similarmente aumenta-se a perda de massa, com redução nas firmezas do fruto e do mesocarpo. Também nesse caso, à medida que aumenta a PM no fruto em fase de amadurecimento, reduz-se a atividade e a contribuição da COX no processo respiratório mitocondrial. Fica, portanto, a indagação: seria possível estimar a participação de cada uma das vias, AOX e COX, a partir de medições da perda de massa e firmeza do fruto, ou mesmo estimar a respiração total a partir da firmeza do mesocarpo? Ainda: em termos práticos, seria possível estabelecer por genótipo de mamão e em condições controladas essas relações entre características físicas e fisiológicas, com elevado grau de confiabilidade, a ponto de as análises mais complexas e onerosas serem estimadas por análises de rotina mais simples e baratas?

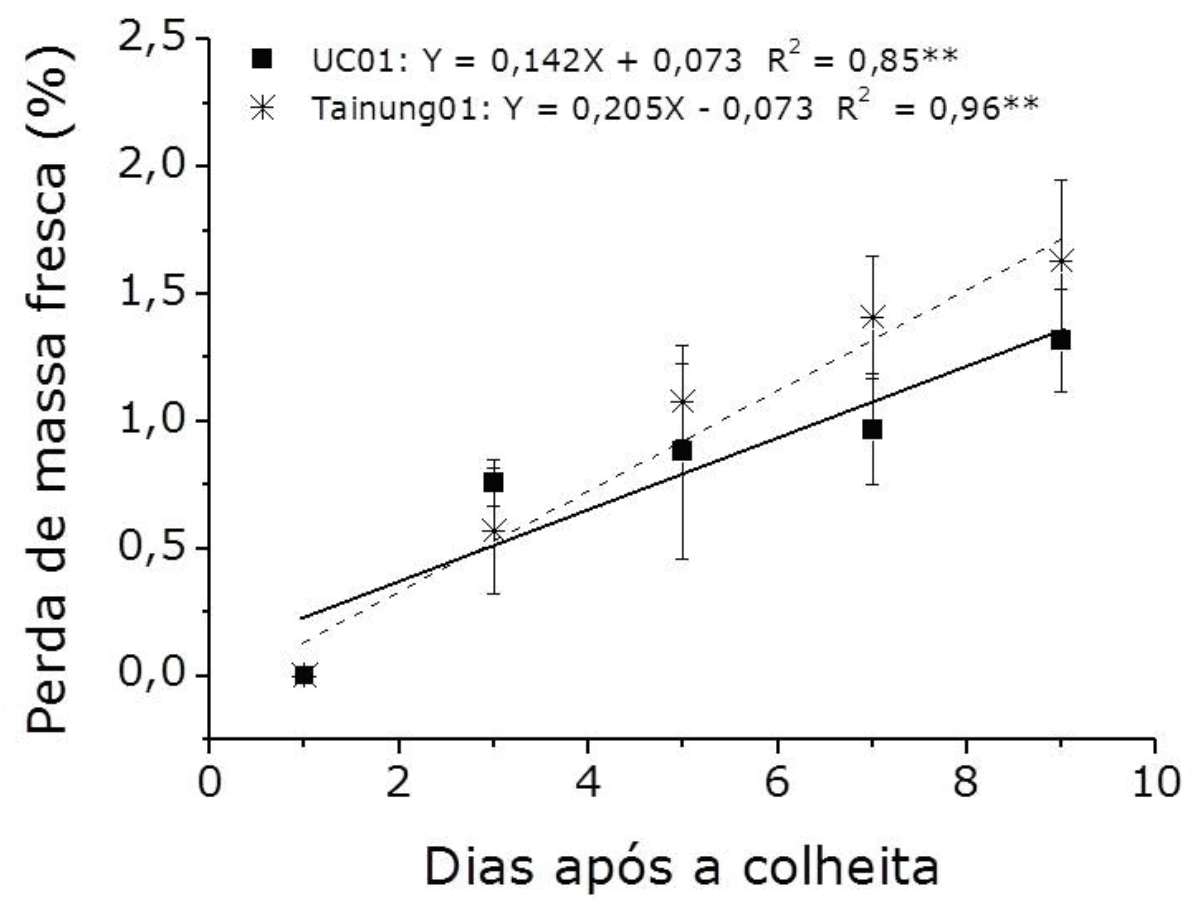

FIGURA 1 - Perda de massa fresca (\%) dos frutos UENF/Caliman01 e Tainung 01 em função do tempo de armazenamento a $25^{\circ} \mathrm{C}$ e UR a $85 \%$. (Média \pm IC, $p \leq 0,05$ ). 
TABELA 1 - Correlação de Pearson entre parâmetros relacionados à atividade respiratória em mitocôndrias isoladas e atributos físicos e químicos associados à qualidade de mamões dos genótipos UENF/ Caliman01 e Tainung01.

\begin{tabular}{ccccccccccc}
\hline & L & C & $h u e$ & PM & FF & FM & SS & AT & SS $/ A T$ & AA \\
\hline AOX & $0,52^{*}$ & $0,45^{*}$ & $-0,53^{*}$ & $0,91^{* *}$ & $-0,72^{* *}$ & $-0,75^{* *}$ & $-0,25^{\text {ns }}$ & $-0,41^{\text {ns }}$ & $0,20^{\text {ns }}$ & $0,28^{\text {ns }}$ \\
COX & $-0,52^{*}$ & $-0,42^{\text {ns }}$ & $0,48^{*}$ & $-0,87^{* *}$ & $0,60^{* *}$ & $0,67^{* *}$ & $0,37^{\text {ns }}$ & $0,46^{*}$ & $-0,16^{\text {ns }}$ & $-0,28^{\text {ns }}$ \\
RT & $-0,51^{*}$ & $-0,58^{* *}$ & $0,64^{* *}$ & $-0,39^{\text {ns }}$ & $0,31^{\text {ns }}$ & $0,56^{* *}$ & $-0,00^{\text {ns }}$ & $0,15^{\text {ns }}$ & $0,02^{\text {ns }}$ & $-0,31^{\text {ns }}$ \\
\hline
\end{tabular}

*: efeito de correlação significativa ao nível de $5 \%$ de probabilidade de erro, **: significativo ao nível de $1 \%$ e ns: efeito não significativo; AOX: participação da oxidase alternativa na RT; COX: participação da citocromo C oxidase na RT; RT: respiração total; L: luminosidade da casca; C: croma da casca; hue: ângulo hue da casca; PM: perda de massa; FF: firmeza do fruto; FM: firmeza do mesocarpo; SS: sólidos solúveis; AT: acidez titulável; SS/AT: razão entre sólidos solúveis e acidez titulável; AA: ácido ascórbico.
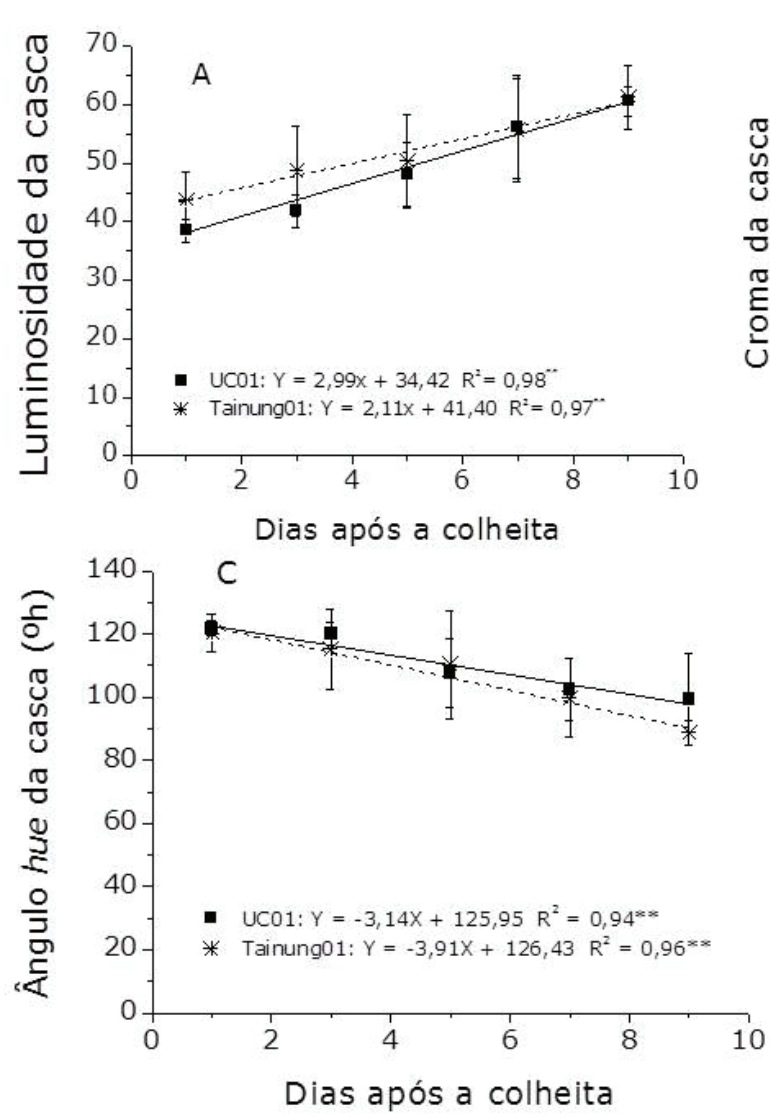

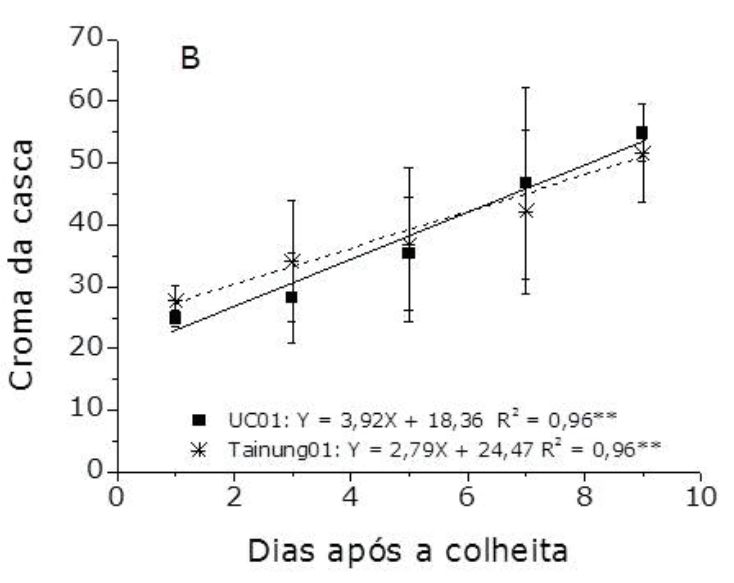

FIGURA 2 - Parâmetros CIELab de luminosidade (A), croma (B) e ângulo hue (C) da casca dos frutos UENF/Caliman01 e Tainung 01 em função do tempo de armazenamento a $25^{\circ} \mathrm{C}$ e UR a $85 \%$. (Média $\pm \mathrm{IC}, p \leq 0,05$ ). 

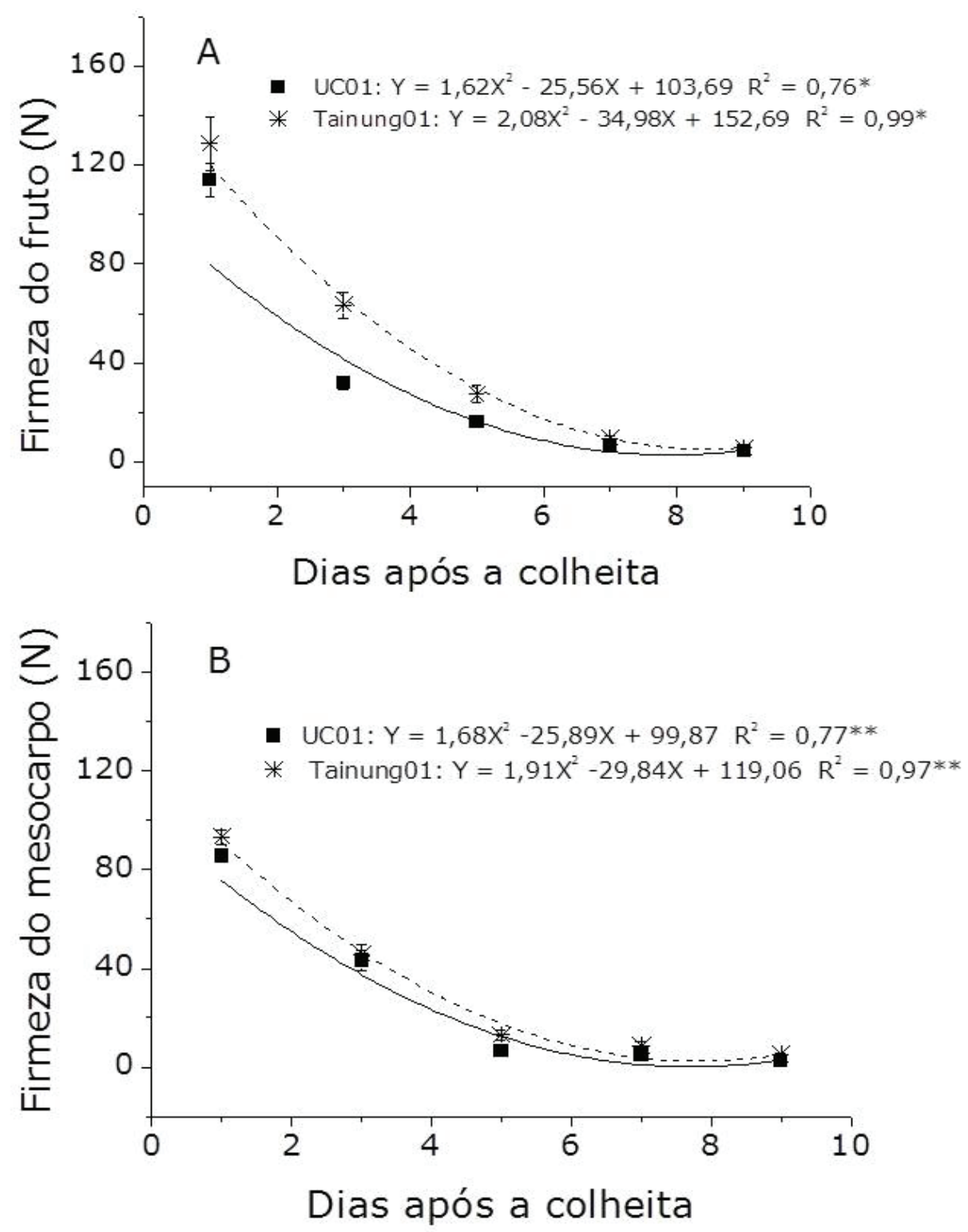

FIGURA 3 - Parâmetros de firmeza do fruto (A) e firmeza do mesocarpo (B) dos frutos UENF/Caliman01 e Tainung 01 em função do tempo de armazenamento a $25^{\circ} \mathrm{C}$ e UR a $85 \%$. (Média $\pm \mathrm{IC}, p \leq 0,05$ ). 


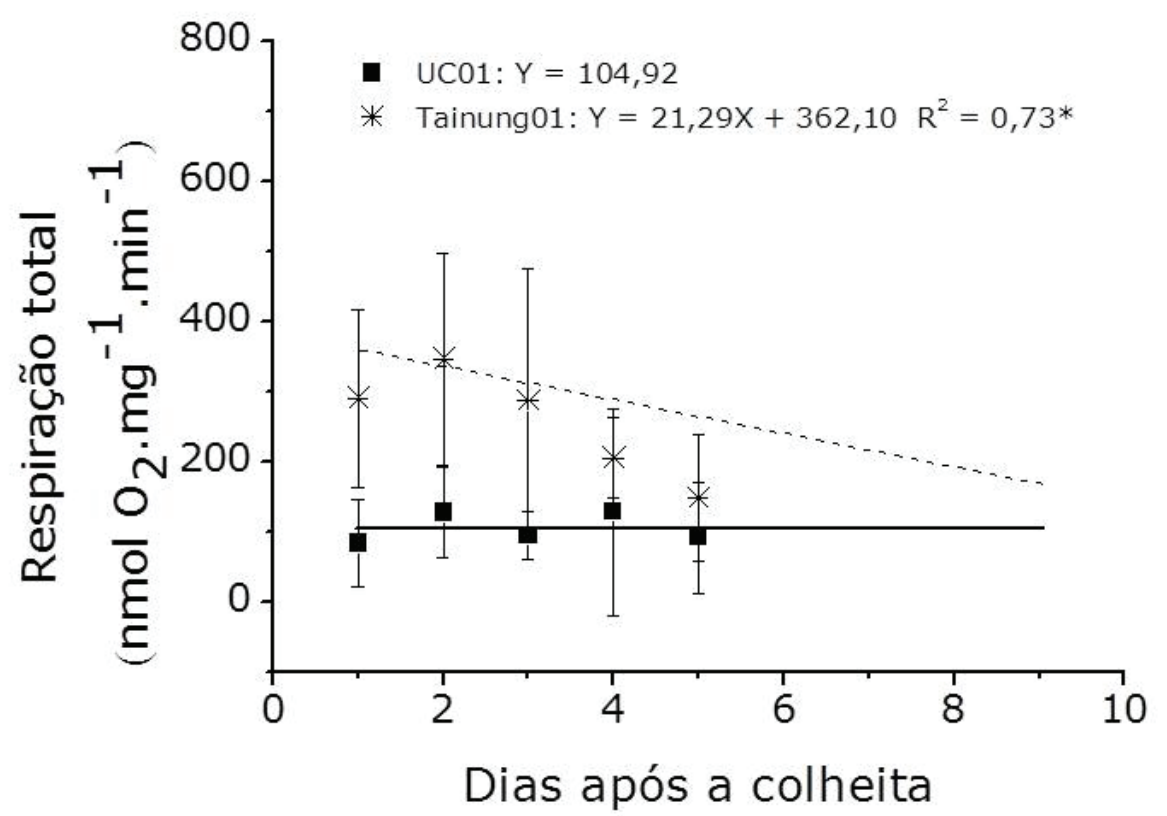

FIGURA 4 - Respiração total $\left(\mathrm{nmol} \mathrm{O} \mathrm{mg}^{-1} \mathrm{~min}^{-1}\right)$ de mitocôndrias isoladas dos frutos UENF/Caliman01 e Tainung 01 em função do tempo de armazenamento a $25^{\circ} \mathrm{C}$ e UR a $85 \%$. (Média $\pm \mathrm{IC}, p \leq 0,05$ ).

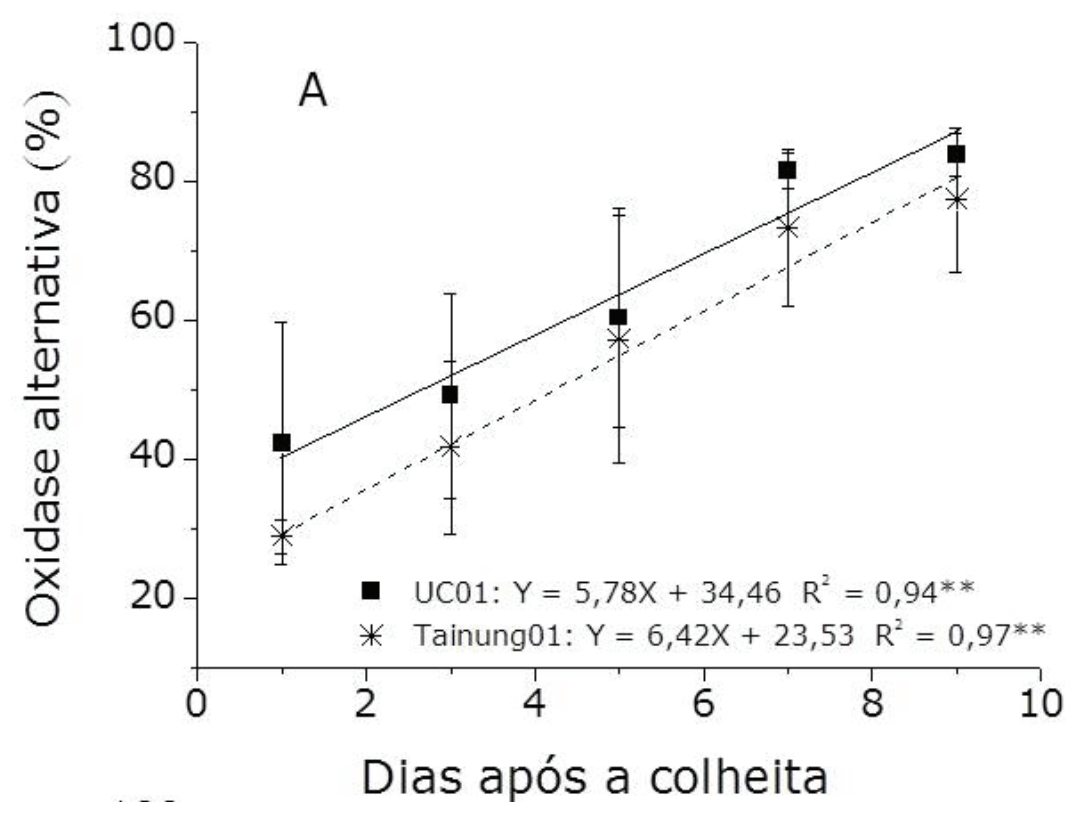

continua... 
continuação.

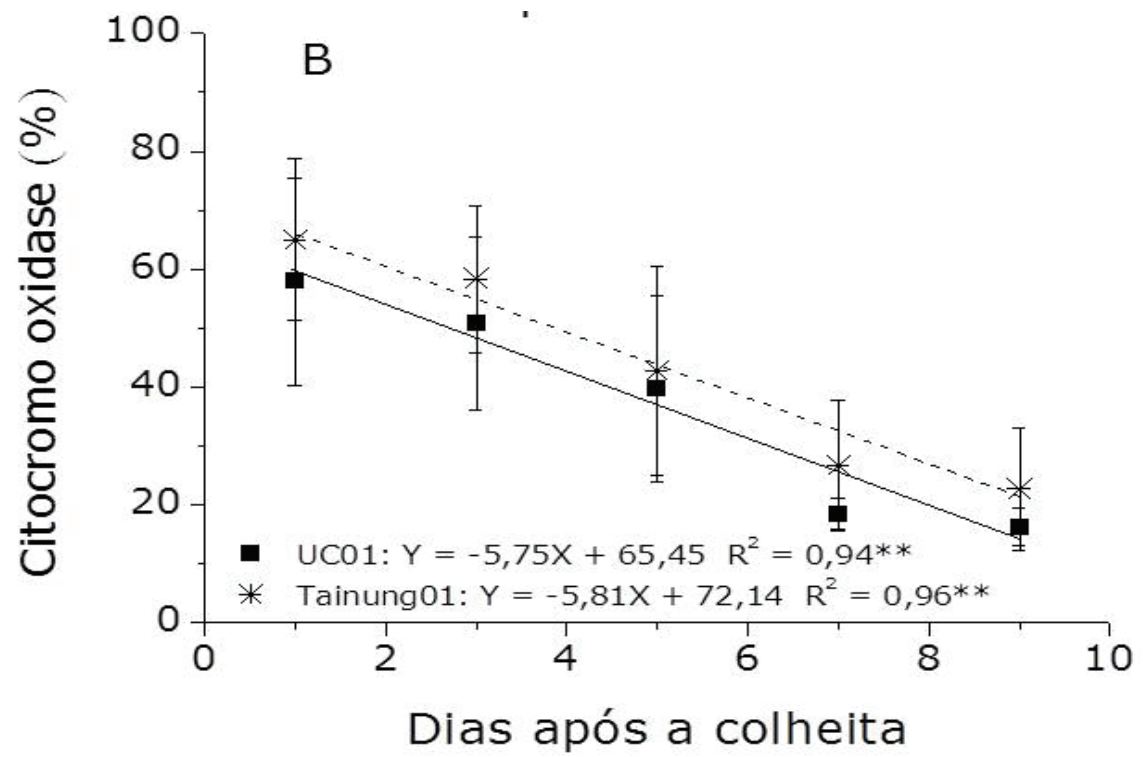

FIGURA 5 - Participação da AOX (A) e da COX (B) em \% da RT de mitocôndrias isoladas dos frutos UENF/Caliman01 e Tainung 01 em função do tempo de armazenamento a $25^{\circ} \mathrm{C}$ e UR a $85 \%$. (Média $\pm \mathrm{IC}, p \leq 0,05)$.

\section{CONCLUSÃO}

A respiração total das mitocôndrias isoladas da polpa do mamão Tainung01 decresceu com o processo de amadurecimento, enquanto no UC01 a mesma foi constante no mesmo período, sendo inferior àquela registrada no Tainung01.

Durante o amadurecimento dos mamões UC01 e Tanung01, a participação da AOX é crescente, enquanto a da COX é decrescente, não mostrando diferença entre os genótipos.

Entre as principais transformações que ocorrem durante o amadurecimento do mamão, as mudanças na coloração da casca não mostraram diferenças entre os híbridos, porém a perda de massa e a firmeza do fruto e do mesocarpo diferiram entre os genótipos, com menor perda de massa para o UC01. Destaque para a perda na firmeza do fruto que foi mais intensa no UC01, principalmente nos três primeiros dias do amadurecimento.

Foram verificadas correlações significativas entre a perda de massa e a firmeza do fruto e do mesocarpo com a participação das vias respiratórias AOX e COX, em ambos os genótipos, assim como entre a respiração total e a firmeza do mesocarpo, o que nos apresenta a possibilidade, em termos práticos, de poder inferir sobre a atividade respiratória do mamão a partir de análises físicas muito simples.

\section{REFERÊNCIAS}

ALMEIDA,A.M.; NAVET, R.; JARMUSZKIEWICZ, W.; VERCESI, A.E.; SLUSE-GOFFART, C.M.; SLUSE, F.E. The energy-conserving and energydissipating processes in mitochondria isolated from wild type and nonripening tomato fruits during development on the plant. Journal of Bioenergetics and Biomembranes, New York, v.34, p.487-498, 2002.

AOAC - Association of Official Analytical Chemists. Official methods of analysis of the Association of Official Analytical Chemists. $17^{\text {th }}$ ed. Washington: AOAC, 2002. p.1115.

ARNHOLDT-SCHMITT, B.; COSTA, J.H.; MELO, D.F. AOX - a functional marker for efficient cell reprogramming under stress? Trends in Plant Science, Cambridge, v.11, n.6, p.281-287, 2006.

AZEVEDO, I.G.; OLIVEIRA, J.G.; SILVA, M.G.; PEREIRA, T.; CORREIA, S.F.; VARGAS, H.; FAÇANHA, A.R. P-type $\mathrm{H}^{+}$-ATPases activity, membrane integrity, and apoplastic $\mathrm{pH}$ during papaya fruit ripening. Postharvest Biology and Technology, Amsterdam, v.48, n.2, p.242-247, 2008. 
BASULTO, F.S.; DUCH, E.S.; GIL, F.E.; PLAZA, R.D.; SAAVEDRA, A.L.; SANTAMARÍA, J.M. Postharvest ripening and maturity indices for maradol papaya. Interciência, Caracas, v.34, n.8, p.583-588, 2009.

BORECKY, J.; VERCESI, A.E. Plant uncoupling mitochondrial protein and alternative oxidase: energy metabolism and stress. Bioscience Report, Abingdon, v.25, n.3/4, p.271-286, 2005.

CALEGARIO, F.F.; COSSO, R.G.; FAGIAN, M.M.; ALMEIDA, F.V.; JARDIM, W.F.; JEZEK, P.; ARRUDA, P.; VERCESI, A.E. Stimulation of potato tuber respiration by cold stress is associated with an increased capacity of both plant uncoupling mitochondrial protein (PUMP) and alternative oxidase. Journal of Bioenergetics and Biomembranes, New York, v.35, n.3, p.211-220, 2003.

CHITARRA, M.I.F; CHITARRA, A.B. Pós-colheita de frutas e hortaliças: fisiologia e manuseio. 2.ed. Lavras: FAEPE, 2005. p.785.

CONSIDINE, M.J.; DALEY, D.O.; WHELAN, J. The expression of alternative oxidase and uncoupling protein during fruit ripening in mango. Plant Physiology, Rockville, v.126, n.4, p.1619-1629, 2001.

CORRÊA, S.F.; MOTA, L.; PAIVA, L.B.; COUTO, F.M.; SILVA, M.G.; OLIVEIRA, J.G.; STHEL, M.S.; VARGAS, H.; MIKLOS, A. Effects of ozone exposure on Golden papaya fruit by photoacoustic phase-resolved method: physiological changes associated with carbon dioxide and ethylene emission rates during ripening. Journal of Applied Physics, Melville, v.109, n.11, p.114701, 2011.

CUQUEL, F.L.; OLIVEIRA, C.F.S.; LAVORANTI, O.J. Sensory profile of eleven peach cultivars. Ciência e Tecnologia de Alimentos, Campinas, v.32, n.1, p.70-75, 2012.

DUQUE, P.; ARRABAÇA, J.D. Respiratory metabolism during cold storage of apple fruit. II. Alternative oxidase is induced at the climacteric. Physiology Plantarum, Malden, v.107, n.1, p.2431, 1999.

FERREIRA, M.D.; SANCHEZ,A.C.; BRAUNBECK, O.A. Colheita e beneficiamento de frutas e hortaliças. São Carlos: Embrapa Instrumentação Agropecuária, 2008. p.144. (Comunicado Técnico, 97) .
FERREIRA, J.P.; SCHMILDT, E.R.; AMARAL, J.A.T.; SCHMILDT, O.; NASCIMENTO, A.L. Enraizamento in vitro de clones de mamoeiro 'Tainung 01'. Revista Ciência Agronômica, Fortaleza, v.42, n.2, p.563-566, 2011.

FONSECA, M.J.O.; LEAL, N.R.; CENCI, S.A.; CECON, P.R.; BRESSAN-SMITH, R.E.; SOARES, A.G. Emissão de etileno e de $\mathrm{CO}_{2}$ em mamão 'Sunrise Solo' e 'Golden'. Revista Brasileira de Fruticultura, Jaboticabal, v.28, n.2, p.322-324, 2006.

FONTES, R.V.; SANTOS, M.P.; FALQUETO, A.R.; SILVA, D.M. Atividade da pectinametilesterase e sua relação com a perda de firmeza da polpa de mamão cv. Sunrise Solo e Tainung. Revista Brasileira de Fruticultura, Jaboticabal, v.30, n.1, p.54-58, 2008.

INIESTRA-GONZÁLEZ, J.J.; LINO-LÓPEZ, G.J.; PAULL, R.E.; DE LA ROSA, A.P.B.; MANCILLAMARGALLI, N.A.; SAÑUDO-BARAJAS, A.J.; IBARRA-JUNQUERA, V.; CHEN, N.J.; HERNÁNDEZ-VELASCO, M.Á.; OSUNACASTRO, J.A. Papaya endoxylanase biochemical characterization and isoforms expressed during fruit ripening. Postharvest Biology and Technology, Amsterdam, v.81, p.13-22, 2013.

INSTITUTO ADOLFO LUTZ. Normas analíticas, métodos químicos e físicos de alimentos. 3. ed. São Paulo: IAL, 1985. v.1, p.553-560.

JACOMINO, A.P.; KLUGE, R.A.; BRACKMANN, A.; CASTRO, P.R.C. Amadurecimento e senescência de mamão com 1-metilciclopropeno. Scientia Agrícola, Piracicaba, v.59, n.2, p.303-308, 2002.

KADENBACH, B.; RAMZAN, R.; WENB, L.; VOGT, S. New extension of the Mitchell Theory for oxidative phosphorylation in mitochondria of living organisms. Biochimica et Biophysica Acta - Bioenergetics, Nijmegen, v.1800, n.3, p.205-212, 2010.

LI-JUN, F.; KAI, S.; MIN, G.; YAN-HONG, Z.; DE-KUN, D.; WU-SHENG, L.; FENG-MING, S.; JING-QUAN, Y. Systemic induction and role of mitochondrial alternative oxidase and nitric oxide in a compatible tomato-tobacco mosaic virus interaction. Molecular Plant-Microbe Interactions, Saint Paul, v.23, n.1, p.39-48, 2010. 
MAZORRA, L.M.; OLIVEIRA, M.G.; SOUZA, A.F.; SILVA, W.B.D.; SANTOS, G.M.D.; SILVA, L.R.A.D.; OLIVEIRA, J.G. Involvement of brassinosteroids and ethylene in the control of mitochondrial electron transport chain in postharvest papaya fruit. Theoretical and Experimental Plant Physiology, v.25, n.3, p.203-212, 2013.

MCDONALD, A.E. Alternative oxidase: an interkingdom perspective on the function and regulation of this broadly distributed 'cyanide-resistant' terminal oxidase. Functional Plant Biology, Collingwood, v.35,n.10, p.535-552, 2008.

McGUIRE, R.G. Reporting of objective color measurements. HortScience, Alexandria, v.27, n.12, p.1254-1255, 1992.

NUNES-NESI, A.; FERNIE, A.R.; STITT, M. Metabolic and signaling aspects underpinning the regulation of plant carbon nitrogen interactions. Molecular Plant, Oxford, v.3, n.6, p.973-996, 2010.

RESENDE, E.C.O.; MARTINS, P.F.; AZEVEDO, R.A.; JACOMINO, A.P.; BRON, I.U. Oxidative processes during 'Golden' papaya fruit ripening. Brazilian Journal of Plant Physiology, Campos dos Goytacazes, v.24, n.2, p.85-94, 2012.

OLIVEIRA, M.G. Armazenamento de frutos de mamoeiro: investigação da participação da oxidase alternativa e da proteína desacopladora na respiração em mitocôndrias isoladas da polpa do fruto. 2012. 107f.Tese (Doutorado em Produção Vegetal) - Universidade Estadual do Norte Fluminense Darcy Ribeiro, Campos dos Goytacazes, 2012.

PEREIRA, T.; ALMEIDA, P.S.G.; AZEVEDO, I.G.; CUNHA, M.; OLIVEIRA, J.G.; SILVA, M.G.; VARGAS, H. Gas diffusion in 'Golden' papaya fruit at different maturity stages. Postharvest Biology and Technology, Amsterdam, v.54, n.3, p.123-130, 2009.

PIMENTEL, J.D.R.; SOUZA, D.S.; OLIVEIRA, T.V.; OLIVEIRA, M.C.; BASTOS, V.S.; CASTRO, A.A. Estudo da conservação de mamão Havaí utilizando películas comestíveis a diferentes temperaturas. Scientia Plena, São Paulo, v.7, n.10, p.1-5, 2011.

PINHEIRO, H.A.; BORGES, R.; SILVA, M.A.P.; CENTENO, D.C. Activity of alternative oxidase and plant uncoupling mitochondrial protein in potato tubers stored at low temperature or submitted to artificial aging. Brazilian Journal of Plant Physiology, Londrina, v.16, n.2, p.69-76, 2004.

SANTOS, C.E.M.; COUTO, F.A.D.A.; SALOMÃO, L.C.C.; CECON, P.R.; JÚNIOR, A.W.; BRUCKNER, C.H. Comportamento pós-colheita de mamões Formosa 'Tainung 01' acondicionados em diferentes embalagens para o transporte. Revista Brasileira de Fruticultura, Jaboticabal, v.30, n.2, p.315-321, 2008.

SOUZA, A.F.; SILVA, W.B.; GONÇALVES, Y.S.; SILVA, M.G.; OLIVEIRA, J.G. Fisiologia do amadurecimento de mamões de variedades comercializadas no Brasil. Revista Brasileira de Fruticultura, Jaboticabal, v.36, n.2, p.34-44, 2014.

SOUZA, M.S.; AZEVEDO, I.G.; CORRÊA, S.F.; SILVA, M.G.; PEREIRA, M.G.; OLIVEIRA, J.G. Resposta da aplicação do 1-MCP em frutos de mamoeiro 'Golden' em diferentes estádios de maturação. Revista Brasileira de Fruticultura, Jaboticabal, v.31, n.3, p.693-700, 2009.

SWEETLOVE, L.J.; TAYLOR, N.L.; LEAVER, C.J. Isolation of intact, functional mitochondria from the model plant Arabidopsis thaliana. Methods in Molecular Biology, Totowa, v.372, p.125-136, 2007.

THUMDEE, S.; MANENOI, A.; CHEN, N.J.; PAULL, R.E. Papaya fruit softening: role of hydrolases. Tropical Plant Biology, New York, v.3, n.2, p.98-109, 2010.

VANLERBERGHE, G.C. Alternative oxidase: a mitochondrial respiratory pathway to maintain metabolic and signaling homeostasis during abiotic and biotic stress in plants. International Journal of Molecular Sciences, Basel, v.14, n.4, p.68056847, 2013.

VERCESI, A.E.; BORECKÝ, J.; MAIA, I.G.; ARRUDA, P.; CUCCOVIA, I.M.; CHAIMOVICH, $\mathrm{H}$. Plant uncoupling mitochondrial proteins. Annual Review of Plant Physiology and Molecular Biology, Palo Alto, v.57, p.383-404, 2006.

XU, F.; YUAN, S.; ZHANG, D.W.; LV, X.; LIN, H.H. The role of alternative oxidase in tomato fruit ripening and its regulatory interaction with ethylene. Journal of Experimental Botany, Oxford, v.63, n.15, p.5705-5716, 2012. 